\title{
Hydraulic Energy Recovery in Displacement Controlled Digital Hydraulic System
}

\author{
M. Heikkilä and M. Linjama \\ Department of Intelligent Hydraulics and Automation, Tampere University of Technology, Tampere, Finland \\ E-mail: mikko.heikkila@tut.fi, matti.linjama@tut.fi
}

\begin{abstract}
Digital hydraulic power management system (DHPMS) is a solution based on the digital pumpmotor technology but has multiple outlets. The outlets are independent of each other and several system pressure levels are allowed. The DHPMS is also capable of transferring energy between the outlets. Is this study, the hydraulic energy recovery is analyzed by simulations of a small excavator crane. One outlet of a 6-piston DHPMS is directly connected to a single-acting lift cylinder while a high pressure accumulator is attached to the other outlet. The results show that the energy can be recovered to the accumulator when the load is lowered. In addition, the peak power of the prime mover reduces significantly when the accumulator energy is utilized.
\end{abstract}

Keywords: Digital hydraulic power management system, displacement control, energy recovery

\section{Introduction}

\subsection{Energy efficiency in hydraulics}

Despite a good efficiency of hydraulic components the overall efficiency of hydraulic systems has been generally very low. Load sensing hydraulics, which is widely used in mobile applications, can have the total efficiency as low as 4 $\%$ [1]. Due to environmental issues and the tightening legislation, more energy efficient hydraulic systems have been studied increasingly.

Inderelst et al. [2] compared a conventional LS-system to five alternative system layouts introduced for excavator work hydraulics. Their simulations showed that most energy was saved in the system where the actuators were controlled by variable displacement pumps. Significant reduction in energy consumption was also achieved when the actuators were controlled by using hydraulic transformers connected to a constant pressure rail also.

Huova et al. [3] have used a digital hydraulic valve system (DVS) in a wheel loader instead of a traditional LS-system and successfully reduced the energy losses. Potential for a $33-63 \%$ reduction in losses in multi-actuator systems was shown by simulations. In addition, it was shown in [4] that the energy efficiency of the DVS can be further improved by utilizing a pressurized tank line. All in all, the trend is clear in modern-day hydraulic research, i.e. to minimize losses while investigating methods for energy recuperation [5], [6], [7] and [8].

\subsection{Displacement controlled hydraulic systems}

Displacement controlled hydraulic systems are potential solution for more energy-efficient mobile machinery; energy-wasting throttling of the flow can be discarded when actuators are controlled directly using variable displacement pumps and motors. Pump displacement control was compared to traditional LS-valve control by Williamson et al. [9]. They constructed dynamic models for both systems and simulated a trench-digging cycle for a mini-excavator. Compared to the traditional system $39 \%$ less energy was consumed when the displacement-controlled excavator was used. In their study, the energy savings were achieved solely through the elimination of flow throttling losses because power recovery was not considered.

Zimmerman and Ivantysynova [10] have developed the displacement control of multi-actuator systems even further. They presented two hybrid hydraulic architectures (parallel hybrid and series-parallel hybrid), which allowed energy to be stored in hydraulic accumulators. Furthermore, the approach enabled the engine load to be controlled actively. Their simulations showed that the rated engine power could be reduced to $50 \%$ when the hybrid systems were used, compared to the rated engine power of the non-hybrid system. They also stated that a parallel hybrid system would reduce the fuel consumption of the non-hybrid displacement controlled system by $18.5 \%$ and the series-parallel hybrid by a corresponding $20.3 \%$.

\subsection{Digital hydraulic power management system}

Digital hydraulic power management system (DHPMS) is one solution towards more energy efficient hydraulic systems [11]. The DHPMS can be considered as a digital pump-motor but in addition, independently controlled outlets enable highly efficient power transfer [12]. There are several applications where the technique can be adapted to and a couple is studied in [13], [14] and [15]. 


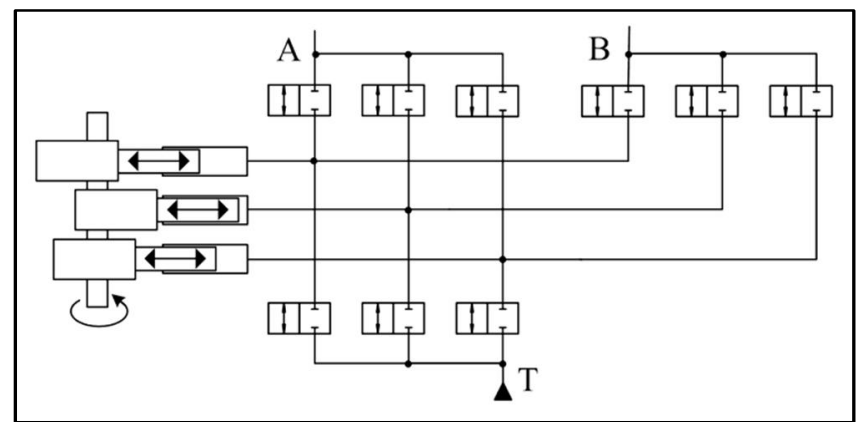

Figure 1. Schematic of 3-piston DHPMS with two outlets

Figure 1 shows a schematic of a 3-piston DHPMS with two independent outlets. Every piston can be connected to each outlet or to the tank via actively controlled on/off valves. The decision for each piston can be made twice in a revolution of the crankshaft; once for the suctions phase and once for the pumping phase. Active valve control also enables optimal pre-compression and pressure release functions; valve timing can be adjusted such that the pressure losses are minimized [12].

Figure 2 shows all periodic pumping and suction cycles of a piston in the case of two independent outlets. Arrows in the drawings stand for flows. Drawings on the first row describe idling when the mean power required from the prime mover is zero (ideal case). However, cases (a2) and (a3) are usually avoided. Drawings (b1) and (b2) shows a normal pumping cycle; fluid is sucked from the tank and pumped to either outlet. Drawings (c1) and (c2) are the motoring cycles respectively. Last two drawings depict the power transfer between the outlets i.e. the fluid is received from one outlet and pumped to another. Of course, it is possible to shift from whichever cycle to any other cycle and, because the pistons are independent of each other the DHPMS can function also as a transformer. It was first shown in [11] that the prime mover power reduces significantly when an accumulator is used as energy source/sink in one outlet of the DHPMS.

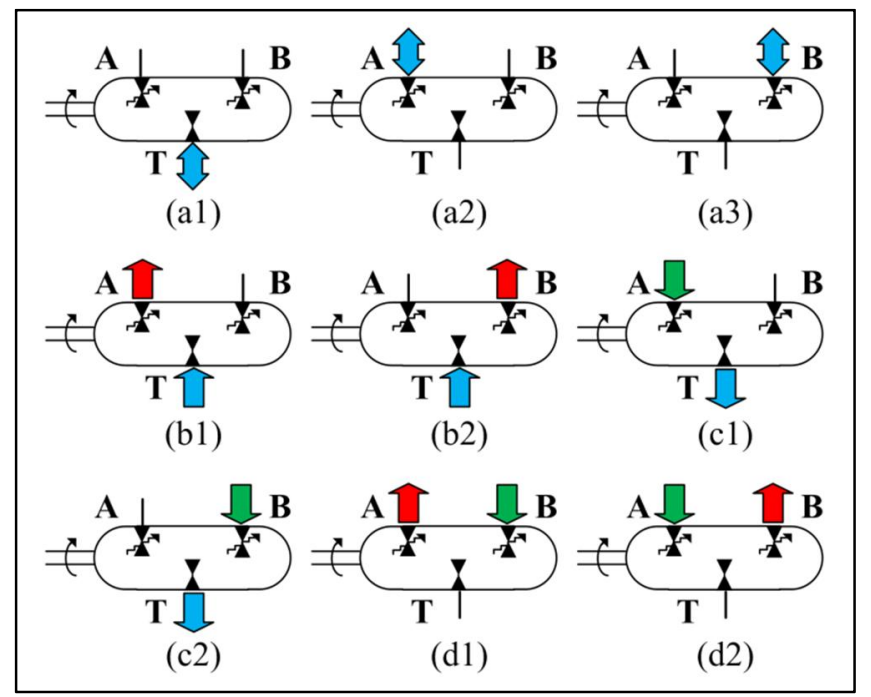

Figure 2. Possible fluid flows in DHPMS

\section{Simulated system}

\subsection{Hydraulics and mechanics}

Figure 3 shows a schematic and CAD-drawing of the studied system. The DHPMS is driven by an electric motor with rotational speed of $750 \mathrm{rpm}$. A flywheel is attached to the DHPMS axis to smooth the motor torque. The outlet B of the DHPMS is connected to the cylinder B-chamber while the A-chamber is connected to a pressurized tank. A static volume with port orifice in the actuator line is used as a damping element. A 4-liter accumulator attached to the DHPMS outlet A is used as energy storage. The tilt cylinder is hydraulically locked close to its minimum length whereas the bucket cylinder and the mechanics have been ignored in the model.

System model is created using MATLAB/Simulink and SimMechanics and the principle of the modeling procedure is similar that presented in [13] and [14]. Induction motor is modeled as a torque source and angular acceleration is calculated considering the moment of inertia of the flywheel. Angular velocity and angle of the motor shaft are the first and the second integrals of the angular acceleration respectively.

Chambers of the DHPMS are modeled as volumes which chance according to sinusoidal motion of the crankshaft. Every chamber can be connected to a tank line or either one of the outlets via on/off control valves. The valves $\left(Q_{\mathrm{n}}=23\right.$ $1 /$ min @ $\left.\Delta p_{\mathrm{n}}=0.5 \mathrm{MPa}\right)$ are modeled using a square root equation of flow and linear spool movement is assumed after the command delay. Ideal model of the DHPMS is used in the study i.e. neither leakages nor torque losses are considered.

Supply line B is modeled as a volume and is connected to a cylinder B-chamber via port orifice $\left(Q_{\mathrm{n}}=1001 / \mathrm{min} @ \Delta p_{\mathrm{n}}\right.$ $=0.5 \mathrm{MPa})$. Port orifice of the A-chamber connects the cylinder to a pressurized tank which is modeled as a constant pressure source. Outlet A of the DHPMS is connected to an accumulator model through a volume and orifice $\left(Q_{\mathrm{n}}=100 \mathrm{l} / \mathrm{min} @ \Delta p_{\mathrm{n}}=0.5 \mathrm{MPa}\right)$. Accumulator is modeled based on an adiabatic change of state by using equations

$p_{0} V_{0}{ }^{\kappa}=p_{1} V_{1}{ }^{\kappa}=p_{2} V_{2}{ }^{\kappa}$

Where $p_{0}$ is the gas pre-charge pressure, $p_{1}$ the gas initial pressure, $p_{2}$ the instantaneous gas pressure and $V_{0}, V_{1}$ and $V_{2}$ the corresponding gas volumes. Adiabatic exponent is a constant $\kappa=1.4$.

Model of the crane consists of five bodies: base, two-part lift boom, tilt boom and load mass. Parts of the lift boom are joined together using a weld while the base and the tilt boom are connected to the lift boom parts through revolute joints. Finally, ball-shaped load mass is welded to the tip of the tilt boom. The booms are modeled as slender rods when calculating the moment of inertia tensors. 


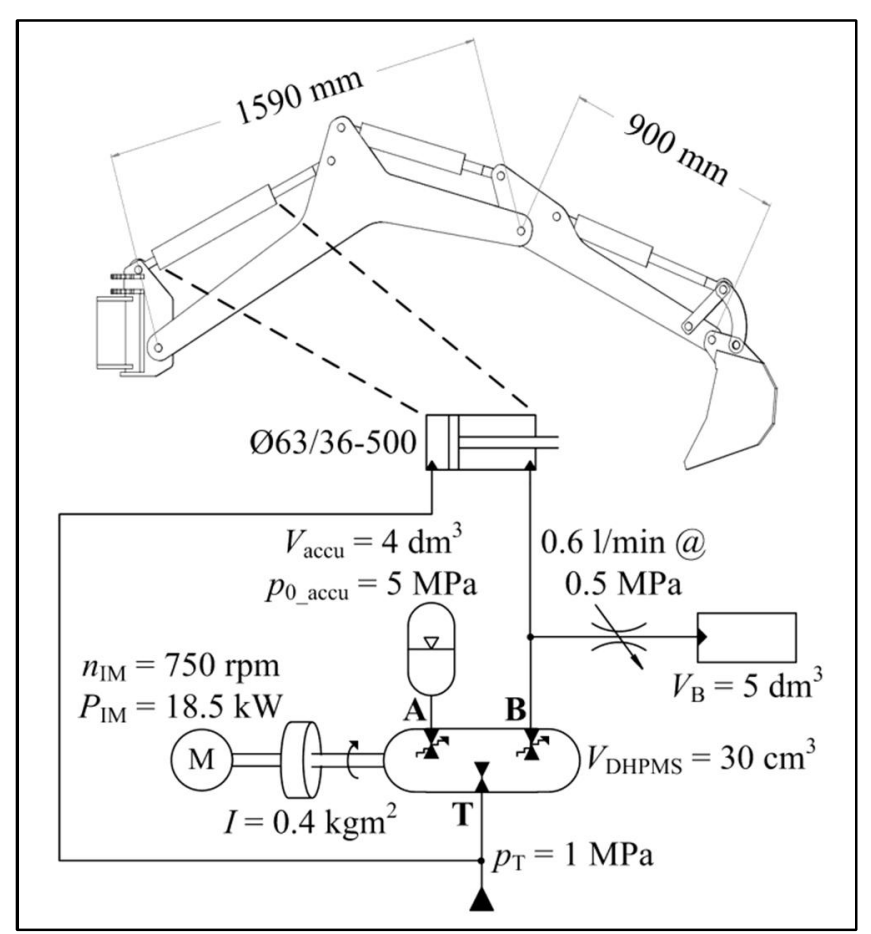

Figure 3. Schematic and CAD-drawing of studied system

\subsection{Control logic}

\subsubsection{Fluid volume control}

Fluid volume control in a direct connection approach is based on stroke-to-stroke control of the DHPMS and is explained in detail in [14]. The piston velocity reference is converted into the fluid volume target and the controller minimizes the error by pumping to or sucking from the actuator line. Of course, the DHPMS can also be left to idle.

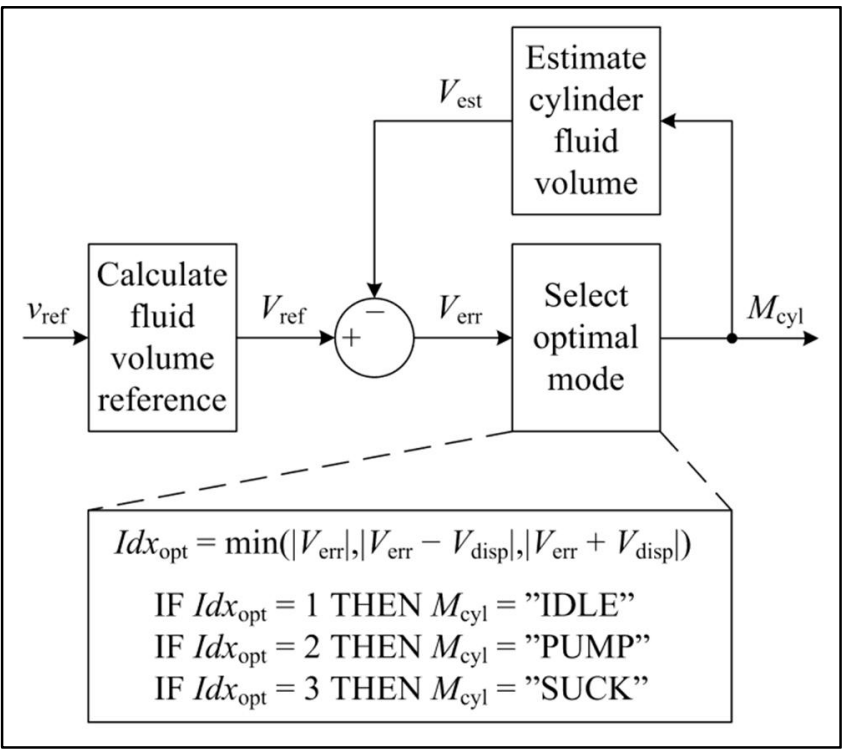

Figure 4. Block diagram of fluid volume control

Figure 4 shows a block diagram of the cylinder mode selection logic. First, the fluid volume reference is calculated from the velocity reference when a piston area is a known parameter. Error in the cylinder fluid volume is further calculated by subtracting the estimated fluid volume from the target value. In this study, the total fluid volume produced by the DHPMS is estimated without utilizing pressure feedback. The piston displacement used by the volume controller is manually adjusted such that positioning accuracy is good enough.

The optimal mode is selected such that the fluid volume error minimizes. There are three mode options for cylinder volume control at every mode selection instant: pumping, suction or idling. Hence, the cylinder volume control is always prioritized over accumulator energy control.

\subsubsection{Accumulator energy control}

Accumulator energy control logic is shown in Figure 5. First, hydraulic total energy in a cylinder outlet is estimated according to a mode outputted from the volume controller. The energy is calculated as a product of theoretical DHPMS piston displacement and measured cylinder pressure. Hydraulic total energy of the DHPMS is further calculated by adding accumulator energy which is estimated similarly that of the cylinder.

At every mode selection instant, the optimal mode for accumulator energy control is determined to minimize consumed hydraulic energy in the outlets of the DHPMS. However, the mode for accumulator control is always selected after the selection of cylinder mode thus the optimal mode cannot be realized every time. Idle-mode is selected for the accumulator whenever the mode of volume control and the optimal accumulator mode conflicts.

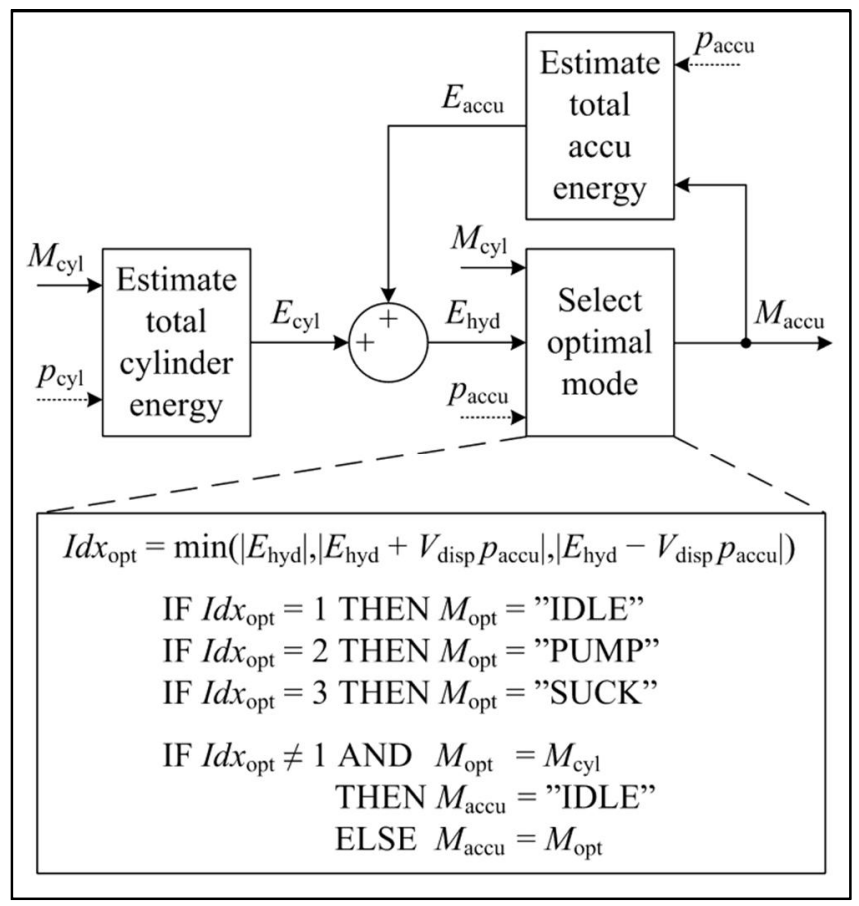

Figure 5. Mode selection logic of accumulator control

Logic for charging the accumulator and controlling the pressure is separate from the energy control. The logic can be realized by using three parameters for the accumulator: 
target pressure, minimum pressure and maximum pressure. The accumulator is charged if the pressure is below the target and the actuator does not require power. However, the optimal target pressure is not studied here. The pressure limits instead are set to prevent too high or low pressure in the accumulator.

\section{Simulation results}

\subsection{Charging of accumulator}

Figure 6 shows power consumption and require energy when the accumulator is charged from 15 to $21 \mathrm{MPa}$ as shown in graph (a). It can be seen that the peak power during charging is over $6 \mathrm{~kW}$ when the maximum flow capacity of the DHPMS is used (blue solid line in graph (b) of Figure 6). The peak power halves when every other piston of the DHPMS is used (red dash line in graph (b) of Figure 6). On the other hand, the charging time doubles respectively. When only one piston in revolution is used for charging the accumulator, the mean power decreases significantly but the peak power is still over $2.5 \mathrm{~kW}$ at maximum (black dot-and-dash line in graph (b) of Figure 6). In this case, $6 \mathrm{MPa}$ increase in accumulator pressure takes over seven seconds. Required input energy is independent of the charging rate in the studied accumulator model as can be seen in graph (c) of Figure 6.

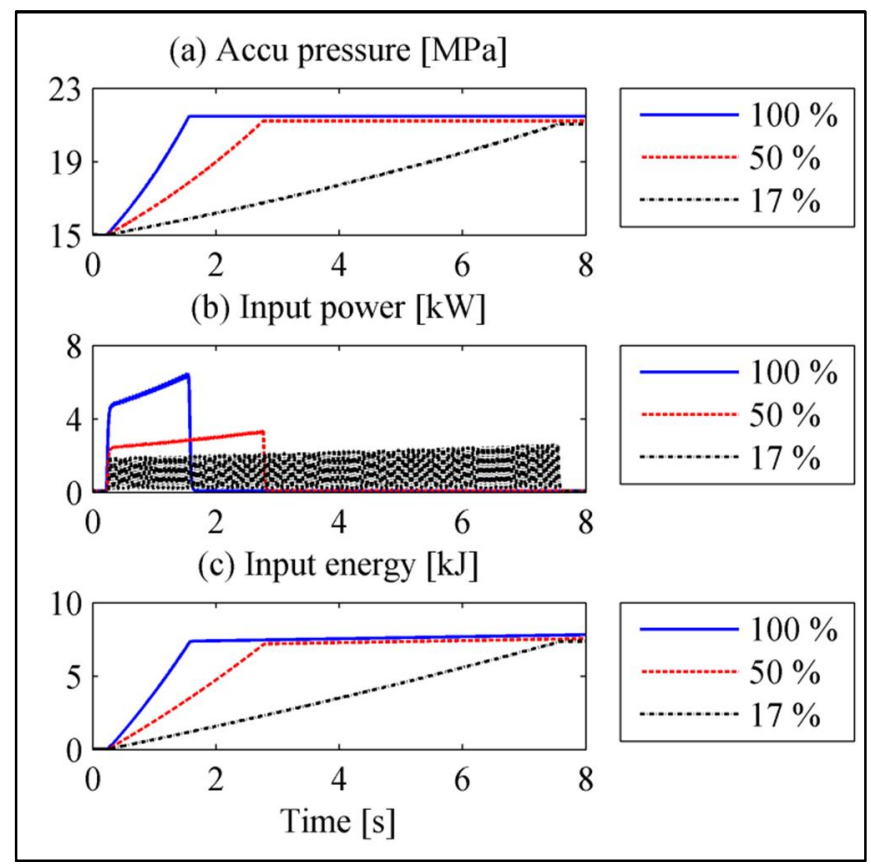

Figure 6. Power consumption during accumulator charging

\subsection{Energy recovery potential of the system}

\subsubsection{Reference simulation}

First, a test trajectory used in the study is simulated without utilizing accumulator energy. Load mass of $400 \mathrm{~kg}$ has been added to a tip of the tilt boom and open-loop fluid volume control is used to drive the lift boom cylinder. Retracting movement of $0.2 \mathrm{~m}$ is performed to lift the boom upward and after that extending movement is done such that the original position is achieved.

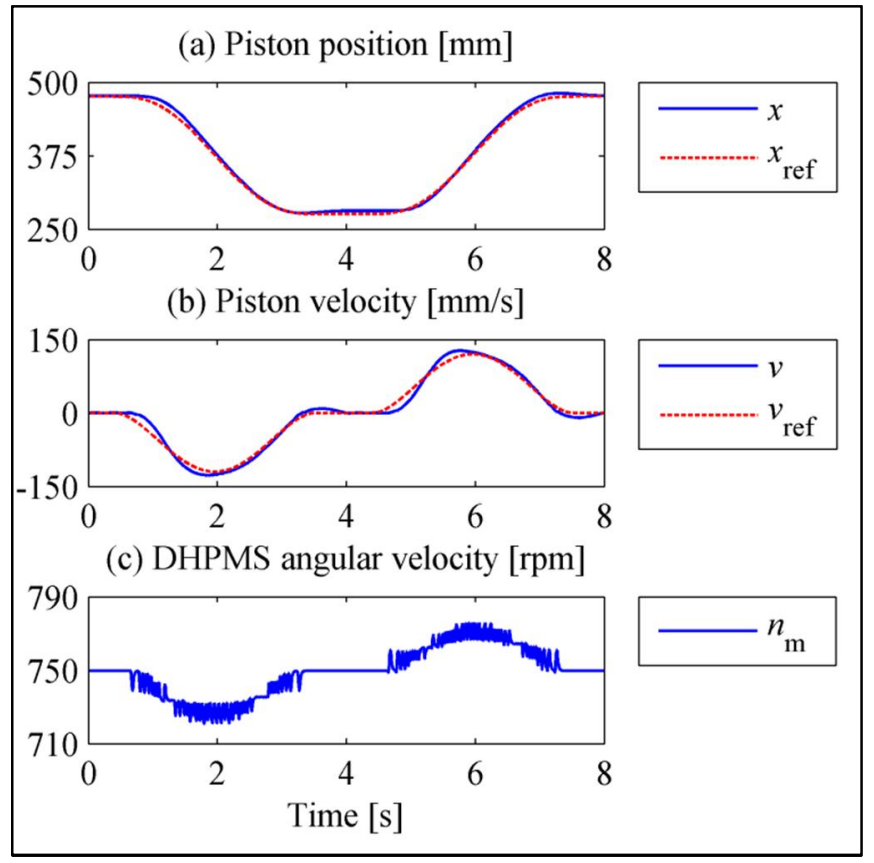

Figure 7. Test trajectory and tracking accuracy

Position tracking is good as shown in graph (a) of Figure 7. However, the effect of large inertial load can be seen during the movement especially in piston velocity (graph (b) of Figure 7). Building up the pressure causes a delay in the beginning of the movement and after that the piston accelerates rapidly to its maximum speed. Natural damping of the displacement controlled system is quite low despite of the attached damping elements. Graph (c) of Figure 7 shows rotational speed of the induction motor. Rotational speed decreases when the DHPMS requires torque and increases when the DHPMS is motoring i.e. the electric motor functions as a generator.

Graph (a) of Figure 8 shows the lift cylinder pressure and accumulator pressure during the simulated trajectory. Pressure in the chamber B varies between 15.2 and 20.5 $\mathrm{MPa}$ when the load mass is $400 \mathrm{~kg}$. The highest and the lowest pressure occur at the beginning of the movements when the inertial load is accelerated. Output power of the system is calculated as a product of generated cylinder force and piston velocity. The power is about $4.5 \mathrm{~kW}$ at maximum when lifting the boom and $-4.2 \mathrm{~kW}$ at minimum during lowering as shown in graph (b) of Figure 8 (red dash line). A blue solid line in the graph (b) of Figure 8 is an input power of the system which is calculated as a product of the motor torque and angular velocity. Required peak power of the electric motor is close to $5.5 \mathrm{~kW}$ and the minimum about $-5.0 \mathrm{~kW}$ correspondingly.

Graph (c) of Figure 8 shows input and output energies during the test trajectory (blue solid line and red dash line). The energies are integrals of the presented input and output powers. It can be seen from the curves that the system can 
recover the energy. The losses are produced solely in on/off control valves of the DHPMS because the torque losses are not considered in the model. However, if the negative input power cannot be utilized by the prime mover the losses are about $7 \mathrm{~kJ}$ which is described by the black dot-and-dash line in graph (c) of Figure 8 (saturated input energy).

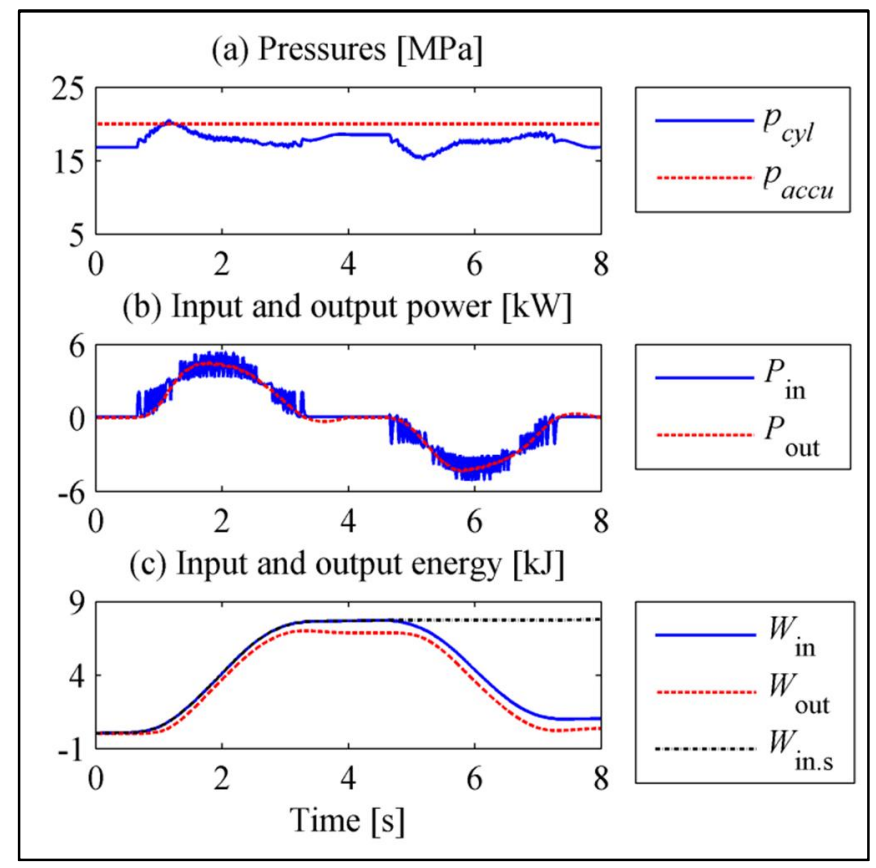

Figure 8. System characteristics without accumulator

\subsubsection{Hydraulic energy recovery}

Figure 9 shows a simulation where the hydraulic energy recovery is enabled and the load mass is $400 \mathrm{~kg}$. The trajectory used is the same that the one in the reference simulation. Initial pressure of the accumulator is $20 \mathrm{MPa}$ as shown in graph (a) of Figure 9 (red dash line). First, the accumulator energy is utilized in lifting the boom and the pressure decreases. On the contrary, the energy is stored in the accumulator when the load is lowered and the pressure rises. Cylinder pressure (blue solid line in graph (a) of Figure 9) is similar than in the reference simulation because the fluid volume control is separate from the accumulator energy control.

Output power shown in graph (b) of Figure 9 is identical to the one in the reference simulation but the peak power required from the induction motor, however, is significantly smaller when accumulator energy is utilized. It can be seen that when the pressures are close in, the input power is smooth and near zero because the ratio of pumping and motoring cycles equals one. Peaks in the power curve are caused by uneven pumping and motoring cycles due to divergent pressures in the outlets of the DHPMS. In this case, the accumulator energy controller chooses the ratio of pumping and motoring cycles such that the mean power of the electric motor is zero which means that the DHPMS functions as a transformer.

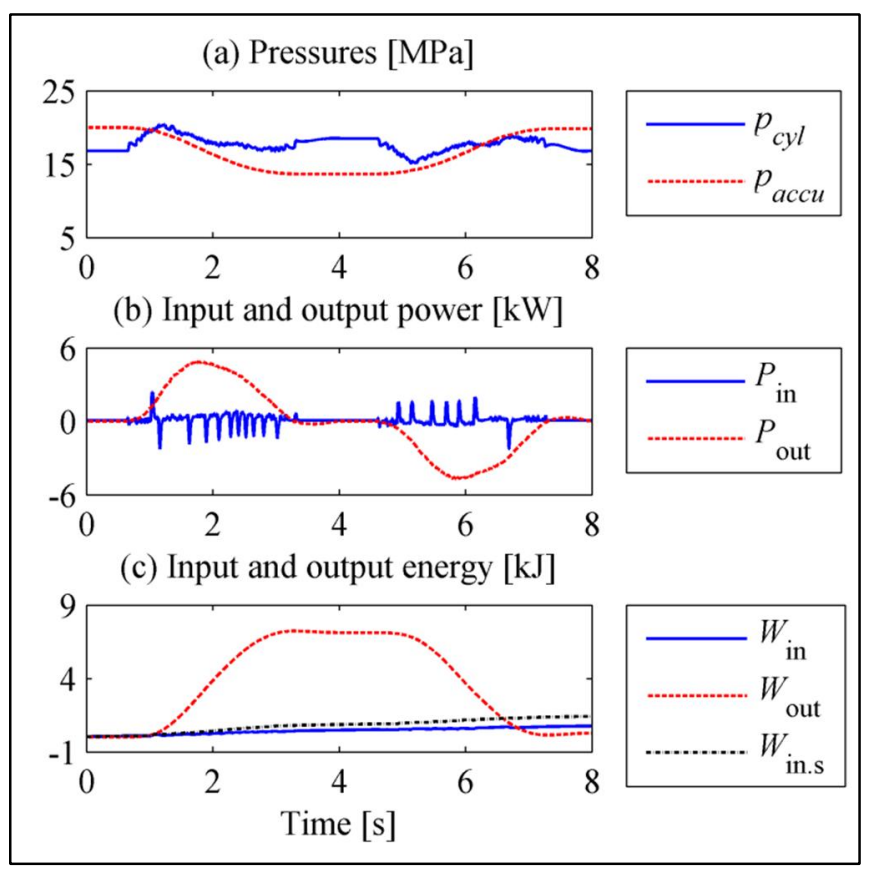

Figure 9. Test cycle with load mass of $400 \mathrm{~kg}$

Graph (c) of Figure 9 shows that the difference between consumed input energy (blue solid line) and its saturated value (black dot-and-dash line) is about $0.5 \mathrm{~kJ}$ at the end of the simulation which means that hydraulic energy recovery possesses good efficiency. It can be seen that the final value of the input energy is somewhat smaller than the one in the reference simulation. Hence, slightly more energy has been taken from the accumulator during lifting than the energy is stored in while motion in the opposite direction. In this paper, however, the object is not to study total losses of the system but the functionality of hydraulic energy recovery.

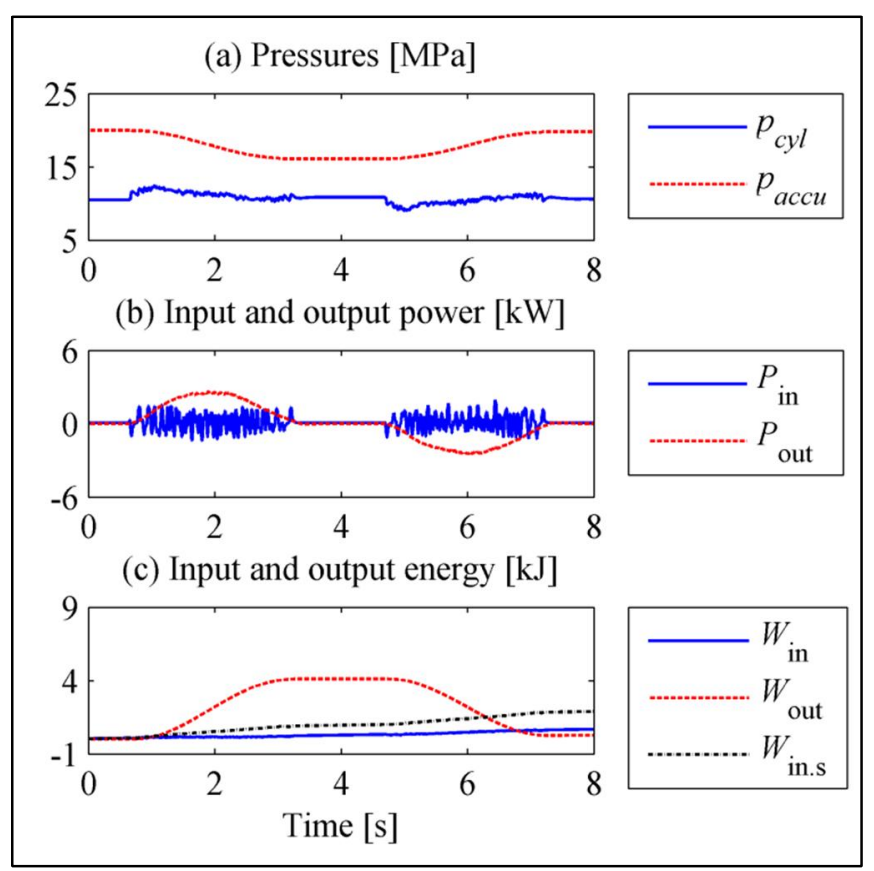

Figure 10. Test cycle with load mass of $200 \mathrm{~kg}$ 
Figure 10 shows the result of a simulation with the load mass of $200 \mathrm{~kg}$. Pressure level of the cylinder is about 11 $\mathrm{MPa}$ (blue solid line) and initial pressure of the accumulator $20 \mathrm{MPa}$ as shown in graph (a) of Figure 10. Compared to the previous case, the change in accumulator energy is smaller during the trajectory due to larger difference between the cylinder pressure and accumulator pressure. In this case, uneven pumping and motoring cycles cause significant ripple in the input power curve, although the mean value is close to zero. Output power instead is between -2.6 and 2.6 $\mathrm{kW}$ in this case.

Graph (c) of Figure 10 shows lower efficiency of the hydraulic energy recovery compared to the previous case. Saturated input energy is now about $2.0 \mathrm{~kJ}$ (black dot-anddash line) at the end of the trajectory and is $1.1 \mathrm{~kJ}$ greater than the total energy of the electric motor (blue solid line). With a load mass of $200 \mathrm{~kg}$, lifting requires about $4 \mathrm{~kJ}$ while lowering returns the same amount of energy (red dash line).

\subsubsection{Improving efficiency of energy recovery}

Simulation examples in the previous chapter show that the hydraulic energy recovery can be realized using the DHPMS. However, peaks in the input power are quite high during uneven pumping and motoring cycles. The reason is a large displacement volume of the pistons; hence the performance can be further improved by diminishing the displacement of the DHPMS.

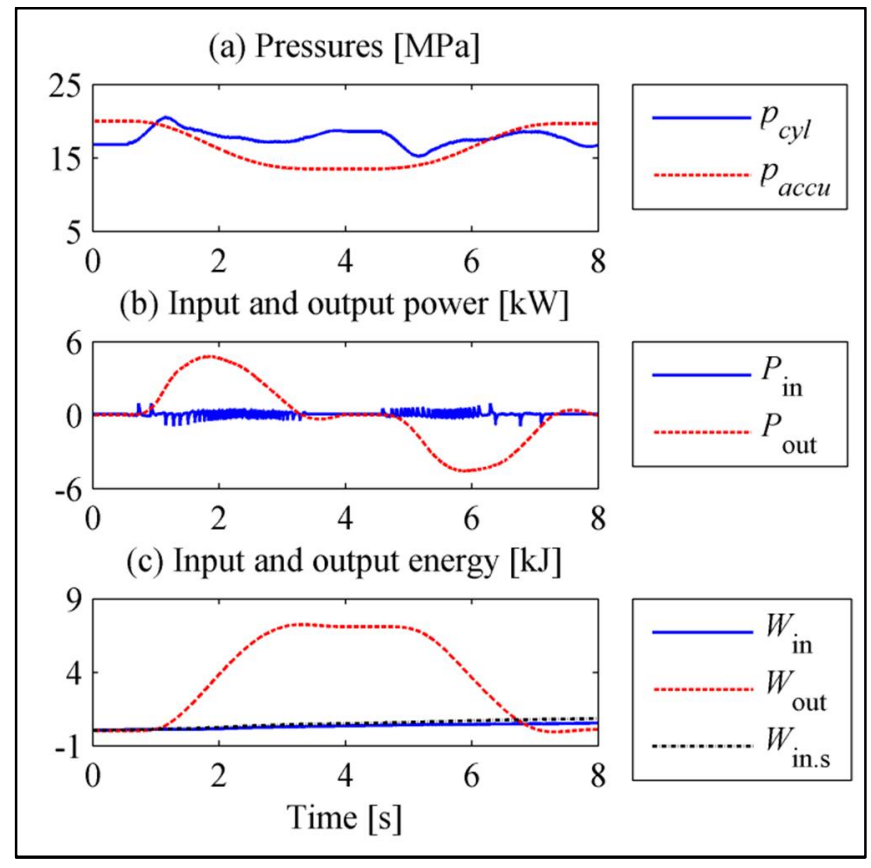

Figure 11. Test cycle with load mass of $400 \mathrm{~kg}$

Figures 11 and 12 show simulations where the piston displacement is a quarter of the original one but the rotational speed of the DHPMS is $3000 \mathrm{rpm}$. Figure 11 shows the pressures, powers and energies when the load mass is $400 \mathrm{~kg}$. It can be seen in graph (a) that the ripple in the cylinder pressure has diminished significantly. Pressure curve of the accumulator has not changed compared to the simulation in the previous chapter. Instead, the difference can be clearly seen in power (blue solid line); the peak power of the electric motor is about one-fourth of the original one. Difference between the end value of input energy (blue solid line) and saturated energy (black dot-anddash line) is only $0.3 \mathrm{~kJ}$ as shown in graph (c) of Figure 11 which means better efficiency of hydraulic energy recovery.

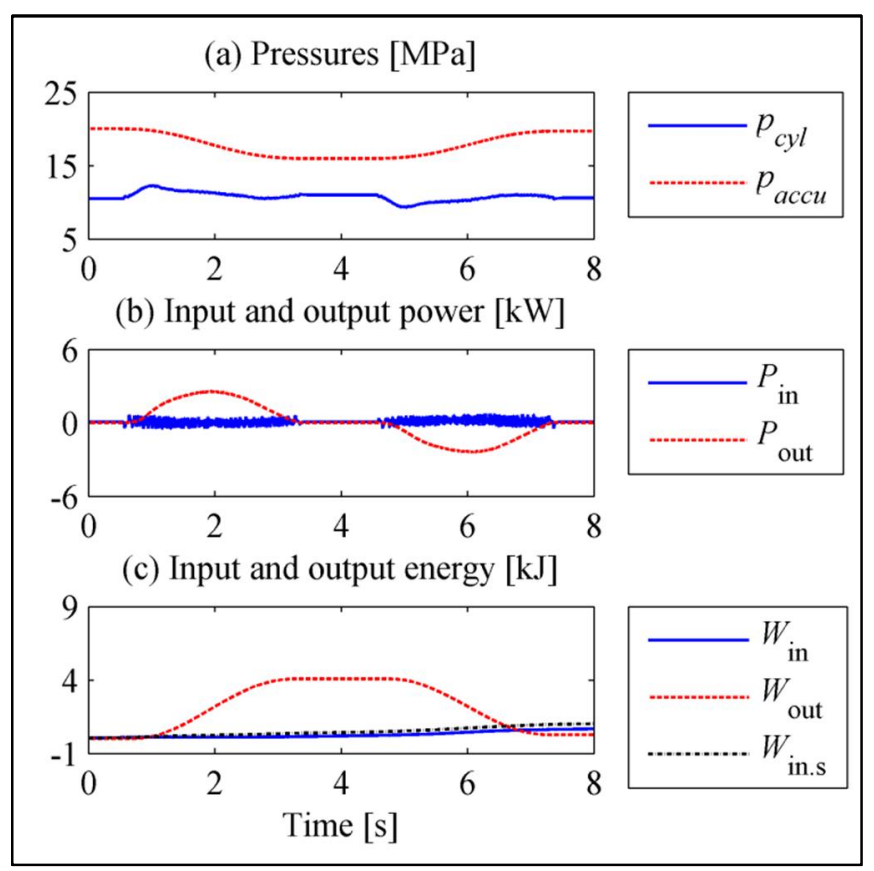

Figure 12. Test cycle with load mass of $200 \mathrm{~kg}$

The effect of smaller displacement volume can be seen even better in Figure 12 which shows a simulation with a load mass of $200 \mathrm{~kg}$. Graph (a) shows smoother cylinder pressure curve and graph (b) diminished ripple in the input power. Efficiency of the hydraulic energy recovery increases considerably compared to the original case. Here, the difference between the total input energy (blue solid line) and saturated energy (black dot-and-dash line) is no more than $0.3 \mathrm{~kJ}$ as shown in graph (c) of Figure 12.

\section{Conclusions and further research}

\subsection{Recovering energy}

In this study, hydraulic energy recovery using a digital hydraulic power management system and high pressure accumulator was tested by simulations. An excavator crane was controlled using a single acting cylinder connected to one outlet of the DHPMS, and the accumulator attached to another outlet was used as energy source/sink. The principle of accumulator energy control was to minimize hydraulic power consumption of the system.

The results show that the hydraulic energy recovery is possible in the displacement controlled digital hydraulic system. Potential energy of the load mass can be efficiently stored into the accumulator during the lowering movement. Noteworthy is that the DHPMS can handle different ratios of pressure levels thanks to the transformer function. Hence, the mean of the input power stays close to zero regardless of the load mass in the tested cases. 


\subsection{Prime mover downsizing}

Instantaneous power required from the prime mover also reduces significantly when the accumulator energy is utilized. Simulations show that the size of the piston displacement has a great effect on the peak power. The system without the hydraulic energy recovery had input power of $5.5 \mathrm{~kW}$ at maximum in the studied trajectory with a load mass of $400 \mathrm{~kg}$. When the accumulator was used the corresponding power was $2.4 \mathrm{~kW}$ or $0.9 \mathrm{~kW}$ depending on the piston displacement. According to the simulations, the highest power is needed when the accumulator is charged to the high pressure; however, the peak power can be controlled by limiting number of the pumping pistons.

\subsection{Next step in study}

In this study, initial pressure of the accumulator was set to $20 \mathrm{MPa}$ regardless of the load pressure. The simulations show that the accumulator can be effectively used as an energy source/sink at different pressure levels. However, optimal pressure level control should be further researched to be able to minimize the input power and to maximize the recovered energy for the most of loadings and duty cycles. In the future, the hydraulic energy recovery will be also tested and the losses analyzed in a real system similar to the one presented in this study.

\section{Acknowledgement}

The research was funded by the Doctoral Program in Concurrent Mechanical Engineering (DPCME) and the Academy of Finland (Grant No. 139540).

\section{References}

[1] Virvalo, T. and Vilenius, M. The Influence of Pumps and Valves on the Efficiency of a Hydraulic Boom. Development in Fluid Power Control of Machinery and Manipulators, Cracow, Poland, 2000.

[2] Inderelst, M., Losse, S., Sgro, S. and Murrenhoff, H. Energy Efficient System Layout for Work Hydraulics of Excavators. The Twelfth Scandinavian International Conference on Fluid Power, SICFP'11, Tampere, Finland, 2011.

[3] Huova, M., Karvonen, M., Ahola, V., Linjama, M., Vilenius, M. Energy Efficient Control of Multiactuator Digital Hydraulic Mobile Machine. The $7^{\text {th }}$ International Fluid Power Conference (IFK), Aachen, Germany, 2010 .

[4] Huova, M. and Linjama, M. Energy Efficient Digital Hydraulic Valve Control Utilizing Pressurized Tank Line. The $8^{\text {th }}$ International Fluid Power Conference (IFK), Dresden, Germany, 2012.

[5] Bishop, E. Digital Hydraulic Transformer Approaching Theoretical Perfection in Hydraulic Drive Efficiency. The $11^{\text {th }}$ Scandinavian International
Conference on Fluid Power, SICFP'09, Linköping, Sweden, 2009.

[6] Kogler, H., Scheidl, R., Ehrentraut, M., Guglielmino, E., Semini, C. and Caldwell, D. A. Compact Hydraulic Switching Converter for Robotic Applications. Bath/ASME Symposium on Fluid Power and Motion Control (FPMC 2010), Bath, UK, 2010.

[7] Juhala, J., Kajaste, J. and Pietola, M. Improving Energy Efficiency of Hydraulic Accumulator. The Twelfth Scandinavian International Conference on Fluid Power, SICFP'11, Tampere, Finland, 2011.

[8] Linjama, M., Vihtanen, H-P., Sipola, A. and Vilenius M. Secondary Controlled Multi-Chamber Cylinder. The 11th Scandinavian International Conference on Fluid Power, SICFP'09, Linköping, Sweden, 2009.

[9] Williamson, C., Zimmerman, J., and Ivantysynova, M. Efficiency Study of an Excavator Hydraulic System Based on Displacement-Controlled Actuators. Bath/ ASME Symposium on Fluid Power and Motion Control (FPMC 2008), Bath, UK, 2008.

[10]Zimmerman, J., and Ivantysynova, M. Hybrid Displacement Controlled Multi-Actuator Hydraulic Systems. The Twelfth Scandinavian International Conference on Fluid Power, SICFP'11, Tampere, Finland, 2011.

[11]Linjama, M., Huhtala, K. Digital Pump-Motor with Independent Outlets. The $11^{\text {th }}$ Scandinavian International Conference on Fluid Power, SICFP'09, Linköping, Sweden, 2009.

[12]Heikkilä, M., Tammisto, J., Huova, M., Huhtala, K., Linjama, M. Experimental Evaluation of a Piston-Type Digital Pump-Motor-Transformer with Two Independent Outlets. Bath/ASME Symposium on Fluid Power and Motion Control (FPMC 2010), Bath, UK, 2010.

[13] Karvonen, M., Heikkilä, M., Huova, M., Linjama, M., Huhtala, K. Simulation study - Improving Efficiency in Mobile Boom Using Digital Hydraulic Power Management System. The Twelfth Scandinavian International Conference on Fluid Power, SICFP'11, Tampere, Finland, 2011.

[14]Heikkilä, M., Linjama, M. Direct Connection of Digital Hydraulic Power Management System and Double Acting Cylinder - A Simulation Study. The Fourth Workshop on Digital Fluid Power (DFP'11), Linz, Austria, 2011.

[15]Heikkilä, M., Linjama, M. Improving Damping Characteristics of Displacement Controlled Digital hydraulic System. The Fifth Workshop on Digital Fluid Power (DFP'12), Tampere, Finland, 2012. 